\section{Massive Necrosis of the Gastric Wall with Gastric Perforation After Injection Therapy of a Bleeding Duodenal Ulcer}

Endoscopic sclerotherapy has established itself as a very effective method in the treatment of bleeding peptic lesions in the upper gastrointestinal tract. Recently, rare but serious and life-threatening complications after sclerotherapy have been published. We report the case of a 57-year-old male, who was transferred to our Interventional Gastroenterology Unit after unsuccessful conservative treatment of upper GI hemorrhage. On admission, he was in good general condition, with normal vital signs and a normal red blood count after previous transfusion. Emergency gastrointestinal endoscopy showed a deep ulcer on the posterior wall of the duodenal bulb (with a black base, Forrest IIc), and sclerotherapy was not performed. Patient was stable for the next three days, after which massive rebleeding occurred.

Emergency gastrointestinal endoscopy at that time showed arterial bleeding (Forrest Ia) from the ulcer on the posterior wall of the duodenal bulb. An injection of $4 \mathrm{ml}$ of 1:5000 epinephrine was not sufficient to control the bleeding; $4 \mathrm{ml}$ of $1 \%$ polidocanol was injected into the lesion, and the bleeding stopped. Cramp-like abdominal pain occurred twelve hours later. The pain gradually became violent, with development of ileus. An urgent laparotomy was performed, and a perforation on the greater curvature of the stomach was found, with diffuse peritonitis. Peritoneal lavage was performed, with subsequent Billroth II resection and external drainage. A duodenal bulbar ulcer was penetrating into the hepatoduodenal ligament.

The resected part of the stomach showed mucosal necrosis along the greater curve, with a perforation of $2 \mathrm{~cm}$ in diameter (Figure 1). Histologic analysis showed mucosal and submucosal necrosis, with cellular detritus and numerous thrombosed submucosal arteries (Figure 2). The patient was discharged from the hospital in good condition three weeks after surgery.

Serious complications of injection therapy are unusual and only sporadically reported: duodenal hematoma (1), extensive necrosis of the gastric mucosa $(2-4)$, gastric ulcer, and cholestasis (5). According to the literature, epinephrine is not an agent that can cause vascular thrombosis. Its effect is mainly vasoconstrictive. Polidocanol and other sclerosing agents cause tissue necrosis, with an increase in the ulcer size and diffuse wall inflammation.

We believe that the reason for the extensive necrosis of the gastric wall in our case was intra-arterial injection of polidocanol with anterograde spreading and subsequent vascular occlusion. Polidocanol was probably directly injected into the gastroduodenal artery, due to the position of the deep ulcer on the posterior wall of the duodenal bulb. It is well known that the gastroduodenal artery passes posteriorly to the first portion of the duodenum before it divides into the

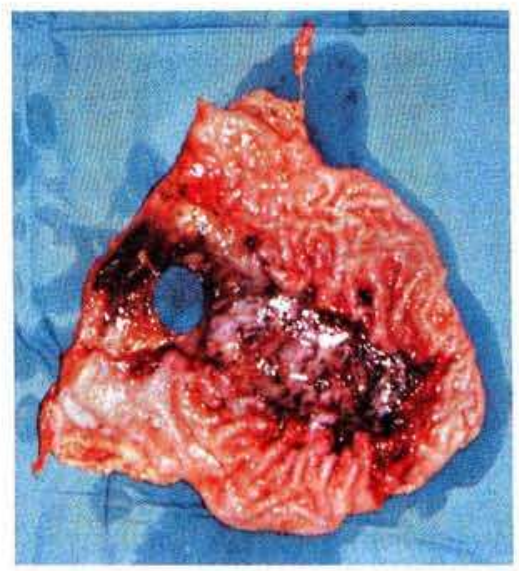

Figure 1: Resected part of the stomach, showing the areas of necrosis and perforation.

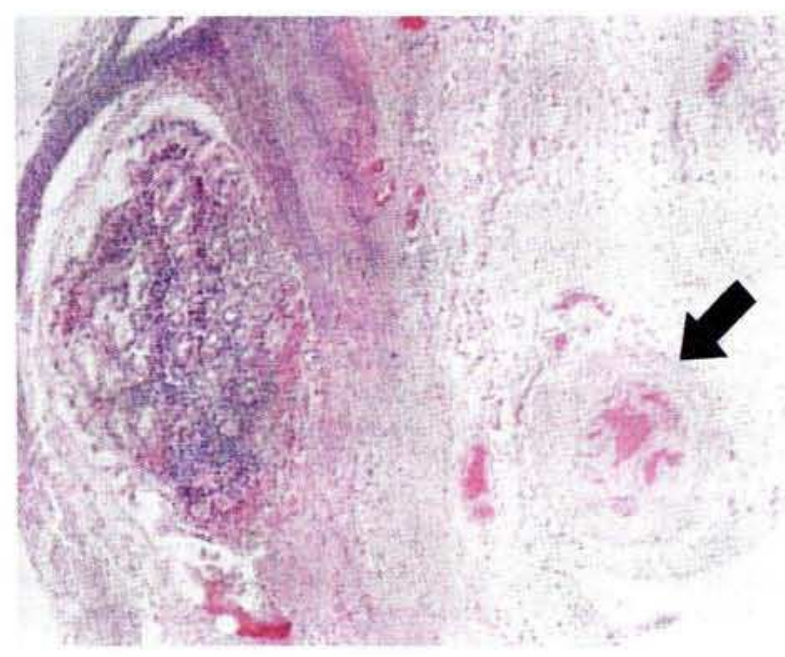

Figure 2: Mucosal necrosis (left) and occluded submucosal artery (arrow). (Hematoxylin-eosin, $\times 40$ ).

right gastroepiploic artery and the superior pancreaticoduodenal artery. The necrotic part of the stomach was supplied with blood mostly by the right gastroepiploic artery, so that one can assume that the polidocanol was directed by the bloodstream mostly into the branches of the right gastroepiploic artery. The final outcome was occlusion of the submucosal arteries in this area, with subsequent necrosis and perforation of the stomach.

\section{References}

1. Peillon $C$, Duhamel D, Lerebours $E$, et al.: Hématome duodénal dissequant: complication grave de l'hémostase endoscopique d'un ulcère duodénal hemoragique. Gastroenterol Clin Biol 1990; 14: 289-291.

2. Loperfido S, Patelli G, La Torre L: Extensive necrosis of gastric mucosa following injection therapy of bleeding peptic ulcer. Endoscopy 1990; 22: 285-286.

3. Chester JF, Hurley PR: Gastric necrosis: a complication of endoscopic sclerosis for bleeding peptic ulcer. Endoscopy 1990; 22: 287.

4. Dell'Abate L, Spaggiari P, Soliani I, et al.: An unusual complication of sclerotherapy. Endoscopy 1991; 23: 352-353. 
5. Raoul JL, Siproudhis L, Ropert A, et al.: Gastric ulcer and cholestasis following injection therapy of bleeding duodenal ulcers. Endoscopy 1991; 23: 351-352.

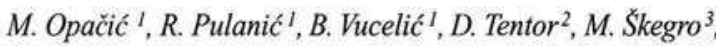
N. Rustemovićl

' Division of Gastroenterology, Department of Internal Medicine

${ }^{2}$ Department of Pathology

${ }^{3}$ Division of Digestive Surgery, Department of Surgery,

University Hospital, Rebro, Zagreb, Croatia
Corresponding Author

M. Opačić, M.D.

Division of Gastroenterology

Department of Internal Medicine

University Hospital, Rebro

Kišpatićeva 12

Zagreb

Croatia 